\title{
The Affective Profiles, Psychological Well-Being, and Harmony: Environmental Mastery and Self-acceptance Predict the Sense of a Harmonious Life
}

Background: An important outcome from the debate on whether wellness equals happiness, is the need of research focusing on how psychological well-being might influence humans' ability to adapt to the changing environment and live in harmony. To get a detailed picture of the influence of positive and negative affect, the current study employed the affective profiles model in which individuals are categorised into groups based on either high positive and low negative affect (self-fulfilling); high positive and high negative affect (high affective); low positive and low negative affect (low affective); and high negative and low positive affect (self-destructive). The aims were to (1) investigate differences between affective profiles in psychological well-being and harmony and (2) how psychological well-being and its dimensions relate to harmony within the four affective profiles.

Method: 500 participants ( mean age $=34.14$ years, $S D .= \pm 12.75$ years; 187 males and 313 females) were recruited online and required to answer three self-report measures: The Positive Affect and Negative Affect Schedule; The Scales of Psychological Well-Being (short version) and The Harmony in Life Scale. We conducted a Multivariate Analysis of Variance where the affective profiles and gender were the independent factors and psychological wellbeing composite score, its six dimensions as well as the harmony in life score were the dependent factors. In addition, we conducted four multi-group (i.e., the four affective profiles) moderation analyses with the psychological well-being dimensions as predictors and harmony in life as the dependent variables.

Results: Individuals categorised as self-fulfilling, as compared to the other profiles, tended to score higher on the psychological well-being dimensions: positive relations, environmental mastery, self-acceptance, autonomy, personal growth, and purpose in life. In addition, $47 \%$ to $66 \%$ of the variance of the harmony in life was explained by the dimensions of psychological well-being within the four affective profiles. Specifically, harmony in life was significantly 
predicted by environmental mastery and self-acceptance across all affective profiles. However, for the low affective group high purpose in life predicted low levels of harmony in life.

Conclusions: The results demonstrated that affective profiles systematically relate to psychological well-being and harmony in life. Notably, individuals categorised as self-fulfilling tended to report higher levels of both psychological well-being and harmony in life when compared with the other profiles. Meanwhile individuals in the self-destructive group reported the lowest levels of psychological well-being and harmony when compared with the three other profiles. It is proposed that self-acceptance and environmental acceptance might enable individuals to go from self-destructive to a self-fulfilling state that also involves harmony in life. 
2 The Affective Profiles, Psychological Well-Being, and Harmony: Environmental Mastery and Self-acceptance Predict the Sense of a Harmonious Life

3

4

5

6
Danilo Garcia $^{1,2 *}$, Ali Al Nima ${ }^{1,3}$, Oscar N. E. Kjell ${ }^{4}$

${ }^{1}$ Network for Empowerment and Well-Being, University of Gothenburg, Gothenburg, Sweden

${ }^{2}$ Center for Ethics, Law and Mental Health (CELAM), University of Gothenburg, Gothenburg,

\author{
Sweden \\ ${ }^{3}$ Department of Psychology. University of Gothenburg, Gothenburg, Sweden \\ ${ }^{4}$ Department of Psychology. Lund University, Lund, Sweden
}

7 * Correspondence concerning this article should be addressed to D. Garcia, CELAM, University

8 of Gothenburg, Wallinsgatan 8, SE 43141 Mölndal, Sweden. E-mail:

9 danilo.garcia@neuro.gu.se; danilo.garcia@euromail.se. 
10 The affective profiles model is based on individuals' affective experience and consist of four

11 different profiles: self-fulfilling (high positive affect, low negative affect), high affective (high

12 positive affect, high negative affect), low affective (low positive affect, low negative affect), and

13 self-destructive (low positive affect, high negative affect) (see among others Norlander, Bood \&

14 Archer, 2002; Bood, Archer \& Norlander, 2004; Norlander, Johansson \& Bood, 2005; Archer,

15 Adriansson, Plancak \& Karlsson, 2007; Karlsson \& Archer, 2007; Palomo, Kostrzewa, Beninger

16 \& Archer, 2007; Palomo, Beninger, Kostrzewa \& Archer, 2008; Archer, Adolfsson \& Karlsson,

17 2008; Schütz, Garcia \& Archer, 2014). The model discerns differences between profiles in

18 measures of negative (i.e., ill-being) and positive (i.e., well-being) mental health (e.g., Garcia,

19 2011, 2012; Garcia \& Archer, 2012; Garcia, Kerekes, Andersson-Arntén \& Archer, 2012; Garcia,

20 Rosenberg, Erlandsson \& Siddiqui, 2010; Garcia \& Siddiqui, 2009a b; Nima, Rosenberg, Archer

$21 \&$ Garcia, 2013; Jimmefors, Garcia \& Archer, In press). Importantly, this approach provides a

22 more informative and detailed picture of the nature of positive and negative affect as compared

23 with simply treating them as two separate variables or adding them together to one mean value

24 (Garcia, 2011).

To the best of our knowledge, the affective profiles model has mostly been examined

26 among Swedes. Nevertheless, the few studies employing the model in other populations show

27 similar results (for studies using Indonesian, Iranian, Dutch, respectively US-residents see:

28 Adrianson, Djamaludin, Neila \& Archer, 2013; Garcia \& Moradi, 2013; Kunst, 2011; Schütz,

29 Sailer, Nima, Rosenberg, Archer \& Garcia, 2013). In general, self-fulfilling individuals report

30 feeling more energetic and optimistic than the other three affective profiles, while all four profiles

31 react differently to stress and have different exercise habits and blood pressure (for a review see

32 Garcia, Ghiabi, Moradi, Siddiqui \& Archer, 2013). Self-fulfilling and high affective individuals

33 show the best performance during stress, have a more active life, and lower blood pressure than

34 individuals with low affective and self-destructive profiles (Norlander et al., 2002; 2005). 
35 Moreover, when compared to self-fulfilling and high affective individuals, low affective

36 individuals have responded maladaptively to induced stress (Norlander et al., 2002); but at the

37 same time low affectives report less stress in their life compared to high affective and low

38 destructive individuals (Norlander et al., 2005). Some researchers have suggested that low

39 affective individuals "go their own way" when choosing their environment. In other words, low

40 affectives are determined and autonomous when avoiding stressful situations in order to avoid

41 pain and displeasure, but also to feel pleasure and satisfaction with their life (Garcia et al., 2010).

42 However, low affective individuals seem to avoid positive meaningful experiences to maintain

43 the status quo of their affectivity levels (i.e., low positive affect and low negative affect), which

44 might give them a sense of balance in life (Garcia et al., 2010).

45 There is, however, a lack of studies in adult populations using the affective profiles model

46 and positive measures of mental health. This is important because the absence of life satisfaction

47 and positive emotions, for example, is more predictive of subsequent mortality and morbidity

48 than the presence of negative emotions (Cloninger, 2004, 2006, 2013; Huppert \& Whittington,

49 2003). In a recent study, Schütz and colleagues (2013) fill this gap in the literature by using a

50 relatively large population of 1,400 US-resident who reported happiness, life satisfaction, and

51 happiness-increasing strategies. Among US-residents, the self-fulfilling individuals reported

52 significantly higher levels of happiness and significantly lower levels of depression than all the

53 individuals in the other three groups (i.e., high affective, low affective, self-destructive). At the

54 other end, the self-destructive group reported significantly higher levels of depression and lower

55 levels of happiness than the other groups (i.e., self-fulfilling, high affective, low affective). These

56 researchers concluded that positive affect might serve as an anti-depressive factor as well as a

57 facilitative factor for happiness and life satisfaction (see also Archer \& Kostrzewa, 2013; Archer,

58 Oscar-Berman, Blum \& Gold, 2013; Lindahl \& Archer, 2013). 
In regards to happiness-increasing strategies, self-fulfilling individuals scored higher in

60 strategies related to agentic (i.e., self-directedness: work on self-control, reach one's full

61 potential, organizing one's life and goals, striving for accomplishment of tasks, proneness to

62 wellness through fitness and flow), communal (i.e., cooperation: supporting and encouraging

63 friends, helping others, interacting with friends, and receiving help from friends), and spiritual

64 values (i.e., self-transcendence: seeking support from faith, performing religious activities,

65 praying) (Schütz et al., 2013). These results are in line with findings about agency and

66 communion's association to mental health, dysfunction and suffering (Cloninger \& Zohar, 2011;

67 Garcia, 2012a; Garcia, Anckarsäter \& Lundström, 2013; Garcia, Lundström, Brä̈dströ̈,

68 Raštam, Cloninger, et al., 2013; Garcia, Nima \& Archer, 2013) and their role in enabling

69 individuals to become happier, healthier, and less depressed (Cloninger, 2013; Johansson

70 Lyssarides, Andersson \& Rousseau, 2013). Schütz and colleagues (2013) suggest that differences

71 between affective profiles imply that promoting positive emotions can positively influence a

72 depressive-to-happy state as well as increasing life satisfaction. Moreover, these researchers

73 suggest that the pursuit of happiness through agentic, communal, and spiritual values leads to a

74 self-fulfilling experience defined as frequently experiencing positive emotions and infrequently

75 experiencing negative emotions (see also Cloninger, 2013; Nima, Archer \& Garcia, 2012, 2013).

76 In this article we address other positive measures of mental health, namely, psychological

77 well-being and harmony in life. Although these measures are related to happiness (i.e., life

78 satisfaction, positive and negative affect; Diener, 1984) they represent distinct conceptualisations

79 of well-being, and thus, measured with different instruments. Psychological well-being, for

80 instance, has been suggested as conceptually different from happiness because it defines intra-

81 personal attributes related to adaptation, self-actualization, and empowerment (Garcia, 2011). An

82 important outcome from the debate on whether wellness equals happiness (see Biswas-Diener,

83 Kashdan \& King, 2009; Delle Fave \& Bassi 2009; Kashdan, Biswas-Diener \& King, 2008; 
84 Garcia, 2013; Ryan \& Huta 2009; Straume \& Vittersø 2012; Waterman, 2008), is the need of

85 research focusing on how psychological well-being might influence humans' ability to adapt to

86 the changing environment and live in harmony. Next, we briefly review these two positive

87 measures of mental health.

88 Psychological Well-Being

89 Ryff (1989) developed a multidimensional model of well-being called psychological well-being,

90 which includes 6 dimensions: positive relations with others, environmental mastery, self-

91 acceptance, autonomy, personal growth, and purpose in life (see Table 1 for definitions). These

92 six dimensions define Ryff's conceptualization of psychological well-being both theoretically and

93 operationally, and they identify what promotes effective mastery of life and emotional and

94 physical health (Ryff, 1989, 1995). For example, among Swedish adolescents, psychological well-

95 being, and especially the self-acceptance and environmental mastery dimensions, strongly relate

96 to high levels of positive affect and life satisfaction (Garcia 2011, 2012; Garcia \& Archer 2012;

97 Garcia \& Siddiqui 2009b).

98 By employing the affective profiles model, researchers have found that self-fulfilling

99 adolescents report higher levels on several of the psychological well-being dimensions. For

100 example, Garcia and Siddiqui (2009b) found that environmental mastery was higher among self-

101 fulfilling individuals as compared to all other profiles (see also Kjell, Nima, Sikström, Archer \&

102 Garcia, 2013). An important observation is also that high and low affective groups differed from

103 each other in psychological well-being dimensions associated to agentic values (e.g., high

104 affectives reported higher personal growth than low affectives) not to those dimensions associated

105 to communal values (i.e., positive relations with others). Purpose in life and personal growth are,

106 indeed, distinctive to the other psychological well-being dimensions (Ryff \& Singer, 1998; Ryff \&

107 Keyes, 1995) — that is, the pursuit of one's true potential or one's great life questions may at times 
108

109

not bring positive emotions and might distort the balance or status quo in one's life. In most of the dimensions, however, the high and low affective individuals showed higher levels than the selfdestructive.

\section{Table 1 should be here}

\section{Harmony in Life}

Harmony in life has been suggested as a complement to satisfaction with life (Kjell, Garcia, Daukantaitè, Hefferon \& Sikström, In press). When measuring life satisfaction, individuals are asked to evaluate if their life is according to their expectations or an ideal (Diener, 1984; Diener, Emmons, Larsen \& Griffin, 1985). In this context, life satisfaction is seen as the cognitive part of happiness, while affect (i.e., positive and negative affect) is seen as the affective part. It has been argued that this evaluation does not by itself represent the full breadth of individuals' cognitive well-being (Kjell, 2011). The assessment of harmony, in contrast, encourages individuals' to assess their global, subjective perception of harmony in life; which includes a global and overall assessment of whether one's life involve balance, mindful nonjudgemental acceptance, fitting in and being attuned with one's life. When comparing the two concepts using quantitative semantics on words that participants have generated to each term, reveals that the concept of satisfaction is significantly more related to achievement, education, work, money and car; whilst the concept of harmony is significantly more related to balance, peace, cooperation, agreement and meditation (Kjell, Garcia, Daukantaite, Hefferon \& Sikström, In press). Harmony and life satisfaction, as most well-being constructs, correlate with each other; but they are also distinct, the sense of a harmonious life explains unique variance in stress and depression (Kjell, Garcia, Daukantaite, Hefferon \& Sikström, In press). Furthermore, harmony, compared to life satisfaction, is more strongly related to the psychological well-being dimensions; meanwhile life satisfaction relates more strongly to happiness (Kjell et al., 2013). 
133 similar results using harmony in life as a construct of cognitive well-being. In other words,

134 individuals with a self-fulfilling profile are hypothesised to report higher levels of harmony in life

135 than the other profiles. Further, as harmony in life and psychological well-being have been found

136 to be particularly related, it is important to further investigate this. In particular, we expected

137 harmony to be related with self-acceptance and environmental mastery among profiles. Although,

138 low affective individuals might "go their own way" (i.e., involving high levels of autonomy or

139 agentic values) when approaching pleasantness; their tendency to avoid pain and meaningful

140 experiences (Garcia et al., 2010) is expected to lower other agentic dimensions of psychological

141 well-being: personal growth and purpose in life. This in turn is expected to relate to a lower sense

142 of a harmony in life.

\section{The present study}

144 The aims were:

145 1. To investigate differences between affective profiles in the different dimensions of 146 psychological well-being and harmony in life.

1472 . To investigate how dimensions of psychological well-being relate to harmony in life 148 within the affective profiles.

\section{Method}

\section{Ethics statement}

151 This research protocol was approved by the Ethics Committee of the University of Gothenburg.

152 Participants' consent was obtained by their agreement to take part of the study, this procedure was

153 accordingly to the review board.

\section{Participants and procedure}

155 The participants $(N=500$, age mean $=34.14$ years $s d .= \pm 12.75$ years; 187 males and 313 156 females) were recruited through Amazons' Mechanical Turk (MTurk; 
157 https://www.mturk.com/mturk/welcome). MTurk allows data collectors to recruit participants

158 (workers) online for completing different tasks for money (for a review on the validity of this

159 method for data collection see Buhrmester, Kwang \& Gosling, 2011). As in Schütz and

160 colleagues' (2013) study, participants in the present study were recruited by the following criteria:

161 US-residency and fluency in English. Participants were paid a wage of two American dollars for 162 completing the task and informed that the study was confidential and voluntary. The participants

163 were presented with a battery of self-reports comprising the well-being measures, as well as 164 questions pertaining age and gender in the following order: demographics, affect measure, 165 psychological well-being scale, and harmony scale.

\section{Instruments}

167 The Positive Affect and Negative Affect Schedule (Watson Clark \& Tellegen, 1988). Participants 168 are instructed to rate to what extent they generally have experienced 20 (10 positive and 10 169 negative) different feelings or emotions during the last weeks, using a 5-point Likert scale $(1=$ 170 very slightly, 5 = extremely). The 10-item positive affect scale includes adjectives such as strong, 171 proud, and interested (Cronbach's $\alpha=.90)$. The 10-item negative affect scale includes adjectives 172 such as afraid, ashamed and nervous (Cronbach's $\alpha=.88$ ).

173 The Scales of Psychological Well-Being (short version; Clarke, Marshall, Ryff \& 174 Wheaton, 2001). The instrument comprises 18 items using a 6-point Likert scale $(1=$ strongly 175 disagree, 6 = strongly agree), 3 items for each of the 6 psychological well-being dimensions: (1) 176 positive relations with others (e.g., "People would describe me as a giving person, willing to 177 share my time with others" Cronbach's $\alpha=.59$ ), (2) environmental mastery (e.g., "I am quite 178 good at managing the responsibilities of my daily life" Cronbach's $\alpha=.76$ ), (3) self-acceptance 179 (e.g., "I like most aspects of my personality" Cronbach's $\alpha=.76)$, (4) autonomy (e.g., "I have 180 confidence in my own opinions, even if they are contrary to the general consensus" Cronbach's $\alpha$ $181=.51)$, (5) personal growth (e.g., "For me, life has been a continuous process of learning, 
182 changing, and growth" Cronbach's $\alpha=.66$ ), and (6) purpose in life ("Some people wander

183 aimlessly through life, but I am not one of them" Cronbach's $\alpha=.32$ ). In the current study, we

184 also computed a composite psychological well-being score (i.e., the sum of the 18 items;

185 Cronbach's $\alpha=.85)$.

186 The Harmony in Life Scale (Kjell, Garcia, Daukantaite, Hefferon \& Sikström, In press).

187 This instrument assesses a global sense of harmony in one's life and consists of 5 statements

188 (e.g., "Most aspects of my life are in balance") for which participants are asked to indicate degree

189 of agreement on a 7-point Likert scale $(1=$ strongly disagree, $7=$ strongly agree $)$. The harmony

190 score was established by summarizing the 5 statements for each participant. Cronbach's $\alpha$ were .

19191 in the present study.

192 Statistical treatment

193 The procedure to create the affective profiles was originally developed by Archer and colleagues 194 (e.g. see Norlander et al., 2002) by dividing self-reported positive affect and negative affect 195 scores into high and low. In the present study, we used the following cut-off points reported by 196 Schütz and colleagues (2013) who used a large population of US-residents: low positive affect = 1973.0 or less; high positive affect $=3.1$ or above; low negative affect $=1.8$ or less; and high 198 negative affect $=1.9$ or above.

199 In the present study the distribution of affective profiles was as follows: 160 self-fulfilling 200 (61 males, 99 females), 66 low affective (23 males, 43 females), 137 high affective (56 males, 81 201 females), and 137 self-destructive (47 males, 90 females). The first analysis, using SPSS (version 202 21), was a Multivariate Analysis of Variance (MANOVA) in which the affective profiles and 203 gender were the independent factors and the dependent factors were the six dimensions of 204 psychological well-being, its composite score, and the harmony in life score. To investigate 205 which dimensions of psychological well-being are related to harmony among profiles we 
performed a path analysis, using AMOS (version 20), in order to estimate interaction/moderation

207 effects between affective profiles as moderator and psychological well-being dimensions as

208 dependent variables upon harmony. The structural equation model of multi-group analysis 209 showed a Chi-square value $=.00 ; D F=00 ;$ comparative fit index $=1.00 ;$ incremental fit index $=$ 2101.00 and normed fit index $=1.00$.

\section{Results}

\section{Differences in psychological well-being and harmony between affective profiles}

213 The affective profiles had a significant effect on the six dimensions of psychological well-being, 214 its' composite score, and the harmony score $(F(21,1396.08)=17.75, p<.001$, Wilks' Lambda $=$.

215 51, Observed Power $=1.00)$. The effect of gender $(p=.21)$ and the interaction of affective profiles 216 and gender $(p=.13)$ were not significant. Self-fulfilling individuals scored higher in all 217 psychological well-being dimensions as compared to all the other profiles: positive relations $218(F(3,492)=55.31, p<.001$, Observed Power $=1.00)$, environmental mastery $(F(3,492)=91.50, p$ $219<.001$, Observed Power $=1.00)$, self-acceptance $(F(3,492)=88.88, p<.001$, Observed Power $220=1.00)$, autonomy $(F(3,492)=11.47, p<.001$, Observed Power $=1.00)$, personal growth $(F(3,492)$

$221=40.72, p<.001$, Observed Power $=1.00)$, purpose in life $(F(3,492)=17.45, p<.001$, Observed

222 Power $=1.00$ ). The only exception was autonomy, in which no difference was found between the 223 low affective and self-fulfilling groups; and for purpose in life, in which no difference was found 224 between high affective and self-fulfilling groups (see Table 2). Instead, low affective scored 225 higher in autonomy compared to self-destructive individuals, while high affective scored higher 226 in purpose in life compared to both low affective and self-destructive individuals.

227 Nevertheless, regarding the psychological well-being composite score, self-fulfilling 228 individuals scored higher than all the other three affective profiles $(F(3,492)=113.53, p<.001$, 
229 Observed Power $=1.00$ ), while both the low and high affective individuals scored higher than the

230 self-destructive individuals (see Table 2). With regard to the harmony in life score, self-fulfilling

231 individuals scored higher than all the other three affective profiles $(F(3,492)=93.06, p<.001$,

232 Observed Power $=1.00$ ). As for the psychological well-being composite score, the low and high

233 affective individuals reported higher harmony score than the self-destructive individuals (see

234 Table 2).

235 Multi-group moderation analysis

236 Four multi-group moderation analyses with the 6 dimensions of psychological well-being as

237 predictors and the harmony in life as the dependent variable showed that $47 \%$ to $66 \%$ of the

238 variance of the harmony in life is explained by the psychological well-being via the four different

239 affective profiles (see Table 3). Harmony in life was significantly predicted by environmental

240 mastery and self-acceptance across all affective profiles (see figures 1-4). However, for the low

241 affective group high purpose in life predicted low levels of harmony in life (see Figure 2).

\section{Discussion}

243 The aim of the present study was twofold: (1) to investigate differences between affective profiles

244 in psychological well-being dimensions and harmony and (2) to investigate how psychological

245 well-being dimensions relate to harmony within the four affective profiles. Overall the results

246 revealed that affective profiles systematically relate to the psychological well-being dimensions

247 as well as harmony. Individuals in the self-destructive group reported the lowest levels of

248 psychological well-being and harmony in life; meanwhile individuals classified as self-fulfilling

249 reported higher levels of psychological well-being and harmony in life, compared to all the other

250 three affective profiles. The results are summarized in Figure 5.

Figure 5 should be here 
253 growth dimensions of psychological well-being. First of all, low affective individuals reported 254 higher autonomy than those categorized as self-destructive and not significantly lower than self255 fulfilling individuals. In other words, despite experiencing low positive affect, low affective 256 individuals seem to feel confident about their own opinions even if those opinions are in contrast 257 to the general consensus. Garcia and colleagues (2010) have earlier suggested that the low 258 affective profiles "go their own way" by using different emotion regulation strategies to avoid 259 displeasure, which also serve as a strategy to feel pleasure (see Higgins, 1997). These researchers 260 showed that low affective individuals actually attenuated their reaction to both negative and 261 positive stimuli by engaging their attention to neutral stimuli (Garcia et al., 2010). This might 262 also explain how individuals categorized as low affective avoid stress in their life (Norlander et 263 al., 2005), which is in line with the second exception regarding the personal growth dimension 264 and high affective individuals.

High affective individuals reported significantly higher levels of personal growth than both self-destructives and low affectives, but still significantly lower than self-fulfilling individuals. Indeed, seeing life as an opportunity to learn and continually grow throughout life is

268 at times rewarding involving positive emotions; but at other times it can be challenging and 269 potentially stressful involving negative emotions (Ryff \& Singer, 1998). For instance, compared 270 to low affective, high affective individuals cope better to induced stress (Norlander et al., 2002)

271 but at the same time report more stress in their life compared to both low affective and self272 fulfilling individuals (Norlander et al., 2005). Although autonomy can be considered as an 273 agentic dimension in which low affectives scored higher than self-destructive, low affectives 274 seem to instead show difficulties with stress that is induced by their surroundings (Norlander et 275 al., 2002), not by peer pressure when they choose to "go their own way" and exert their 276 autonomy (Garcia et al., 2010). In other words, experiencing life as a growing experience and a 
277 greater purpose, which is related to high affectivity, might be one of the experiences low affective

278 individuals will try to avoid.

279 Across affective profiles, harmony in life is related to both self-acceptance and

280 environmental mastery. This suggests that a harmonious life might come from accepting all parts

281 of the self and one's past as well as from the individual's ability to fit in with environments

282 suitable for their strengths. This is actually a good description of the process of empowerment, a

283 process in which the individual is strengthened to be proactive, non-judgemental, responsible for

284 his own actions, in control of her/his own life, and responsible by helping others (Jimmefors et

285 al., In press). It is worth pointing out that as a concept, harmony stress accepting and adapting to

286 the surroundings meanwhile environmental mastery emphasise creating and choosing

287 surroundings. Generally though, these two dimensions are seen to define adaptation to the self

288 and to the environment, which in turn has been associated to the individuals' level of self-

289 awareness (Cloninger, 2004). High levels on the agentic dimension purpose in life were,

290 however, related to low levels of harmony in life among low affective individuals.

291 The purpose in life dimension comprises attitudes such as goal-setting and planning one's

292 future. This approach to life can be seen as striving to promote pleasure and avoiding displeasure

293 by accomplishments - the individual focus on reaching goals because the anticipated rewarding

294 experience of achieving them but also because the expected pain of failure (Higgins, 1997). This

295 approaching focused behaviour stands in contrast to low affectives' avoidance tendency (Garcia

296 et al., 2010). Indeed, individuals feel more at ease and in balance when using strategies that are

297 attuned with their approaching/avoiding tendencies (Higgins, 1997). Indeed, low affective

298 individuals scored lower than high positive affect individuals (i.e., high affective and self-

299 fulfilling) in the purpose in life dimension. We suggest that this does not mean that low affectives

300 should avoid having a purpose in life. After all, the absence of positive emotions, for example, is

301 more predictive of subsequent mortality and morbidity than the presence of negative emotions 
302 (Cloninger, 2004, 2006; Huppert \& Whittington, 2003). At times individuals might need to loose

303 the status quo in order to promote positive emotions and resilience, while at times individuals

304 need to focus on being in harmony with their environment.

305 Limitations and inquiries for further research

306 Although different studies suggest that the quality of the data collected through MTurk meets

307 academic standards and is demographically diverse (Buhrmester et al., 2011; Paolacci, Chandler

308 \& Ipeirotis, 2010; Horton, Rand \& Zeckhauser) it is plausible to point out some potential issues,

309 such as, workers' attention levels, cross-talk between participants, and the fact that participants

310 get remuneration for their answers (Buhrmester et al., 2011). Nevertheless, MTurk is not only

311 suggested as a valid tool for collecting data using personality scales (Buhrmester et al., 2011), but

312 also health measures using MTurk data shows satisfactory internal as well as test-retest reliability

313 (Shapiro, Chandler \& Mueller, 2013), and payment amount does not seem to affect data quality

314 (Buhrmester et al., 2011). Moreover, remuneration in MTurk is usually small and workers report

315 being intrinsically motivated (e.g., for enjoyment) to take part in surveys (Buhrmester et al., 316 2011).

With regard to the psychological well-being dimensions, some showed low reliability

318 (e.g., purpose in life Cronbach's $\alpha=.32$ ); which potentially may question some of the findings.

319 Nevertheless, the internal reliability of the short version used in the present study is almost the

320 same as those obtained by Clarke and colleagues (2001). For instance, descriptive data generated

321 with this short measure are consistent with those found with the larger, more reliable 120-item

322 version (Clarke et al., 2001). Moreover, future research needs to randomize the order in which the

323 instruments are presented to participants to ensure that responses to survey questions are not

324 affected by the order of the instruments (Lavrakas, 2008).

325 Nevertheless, one remaining question is why the positive relations with others dimension

326 was not associated to the sense of a harmonious life. After all, positive and warmth relations with 
327 significant others are constantly associated with a happy and satisfied life (e.g., Garcia \&

328 Sikström, 2013). In addition -after self-acceptance and environmental mastery- positive relations

329 with others has been found to show the third strongest correlation to harmony (Kjell, Garcia,

330 Daukantaitè, Hefferon \& Sikström, In press). However, it has previously been argued that the

331 positive relations with others dimension involves a rather self-centered perspective to

332 relationships (e.g. Christopher, 1999), which perhaps makes it less in tune with the concept of

333 harmony in life. Another explanation might be that creating and keeping social relationships

334 involves both tolerance and empathy towards others (Cloninger, 2004). While social tolerance

335 might involve adaptation to one's environment, empathy involves putting oneself in the place of

336 others and perhaps disturbing one’s inner harmony.

337 In addition, it has been argued that affect as measured in this study, involves rather self-

338 centered and high arousal emotions (e.g., Christopher, 1999; Russell \& Feldman Barrett, 1999;

339 Yik, Russell \& Feldman Barrett, 1999); whilst leaving out more other-centered and low arousal

340 emotions such as feeling compassion, at peace, and love, which might be more in tune with being

341 in harmony. Future research might benefit from also employing an emotion instrument more in

342 line with harmony as this might potentially enrich the investigations of the affective profiles.

343 Finally, it is plausible to criticize the validity of the procedure used to differentiate the

344 four affective profiles $\square$ scores just-above and just-below the median become high and low by fiat,

345 not by reality (Schütz, Archer \& Garcia, 2013). Nevertheless, MacDonald \& Kormi-Nouri (2013)

346 used k-means cluster analysis to test if the affective profiles model emerged as theorized by

347 Archer and colleagues. The affective profiles model was replicated using the k-means cluster

348 analysis and the four affective profiles emerged as the combinations of high vs. low affectivity.

349 The procedure used by these researchers is useful for person-oriented analyses (see Bergman,

350 Magnusson et al., 2003), thus, suggesting the original procedure by Archer as valid.

$351 \quad$ Final remarks 
352 The self-fulfilling state, defined as frequently experiencing positive emotions and infrequently

353 experiencing negative emotions, is not only related to more life satisfaction but also to the sense

354 of a harmonious life. Further, an approach focus in life seems to relate to less harmony in life for

355 individuals who prefer to avoid displeasure and staying in a low affective state. Importantly,

356 acceptance of the self as well as environmental mastery might enable individuals with different

357 affective profiles to have the sense of harmony in life.

358 "He who lives in harmony

359 with himself, lives in harmony

360 with the universe"

361 Marcus Aurelius 
References

363 Adrianson, L., Djumaludin, A., Neila, R., \& Archer, T. (2013). Cultural influences upon health, 364 affect, self-esteem and impulsiveness: An Indonesian-Swedish comparison. International Journal of Research Studies in Psychology. DOI: 10.5861/ijrsp.2013.228.

Archer, T., Adolfsson, B., \& Karlsson, E. (2008).Affective personality as cognitive-emotional presymptom profiles regulatory for self-reported health predispositions.Neurotoxicity Research, 14, 21-44.

Archer, T., Adrianson, L., Plancak, A., \& Karlsson, E. (2007). Influence of affective personality on cog- nitive-mediated emotional processing: Need for empowerment. European Journal of Psychiatry, 21, 21-44.

Archer, T., \& Kostrzewa, R. M. (2013). The inductive agency of stress: From periatal to adolescent induction. In G. Laviola \& S. Macrì (Eds.), Adaptive and maladaptive aspects of developmental stress, current topics in neurotoxicity (Vol. 3, pp. 1-20). New York: Springer. doi:10.1007/978-1-4614- 5605-6_1.

Archer, T., Oscar-Berman, M., Blum, K., \& Gold, M. S. (2013). Epigenetic modulation of mood disorders.Journal of Genetic Syndromes \& Gene Therapy, 4, 120133.doi:10.4172/2157-7412.1000120.

Bergman, L. R., Magnusson, D., \& El-Khouri, B. M. (2003). Studying individual development in an interindividual context: A person-oriented approach. Mahwah, NJ: Lawrence Erlbaum.

382 Biswas-Diener, R., Kashdan, T., \& King, L. A. (2009). Two traditions of happiness research, not 383 two distinct types of happiness. Journal of Positive Psychology, 4, 208-211.

384 Bood, S. Å., Archer, T., \&Norlander, T. (2004). Affective personality in relation to general 385 personality, self-reported stress, coping and optimism. Individual Differences Research, 386 2, 26-37. 
387 Buhrmester, M. D., Kwang, T., \& Gosling, S. D. (2011). Amazon's Mechanical Turk: A New

390 Clarke, P. J., Marshall, V. M., Ryff, C. D., \& Wheaton, B. (2001). Measuring psychological wellbeing in the Canadian study of health and aging. International Psychogeriatrics, 13, 7990.

Cloninger, C. R. (2004). Feeling good: The science of well-being. New York: Oxford University 394 Press.

Cloninger, C. R. (2006). Fostering spirituality and well-being in clinical practice. Psychiatric Annals, 36, 1-6.

Cloninger, C. R. (2013). What makes people healthy, happy, and fulfilled in the face of current world challenges? Mens Sana Monographs, 1, 16-24.

Cloninger, C. R., \& Zohar, A. H. (2011). Personality and the perception of health and 400 happiness.Journal of Affective Disorders, 128, 24-32.

401

Christopher, J. C. (1999). Situating psychological well-being: Exploring the cultural roots of its

Delle Fave, A., \& Bassi, M. (2009). The contribution of diversity to happiness research. The 404 Journal of Positive Psychology, 4, 205-207.

Diener, E (1984). Subjective well-being. Psychological Bulletin, 95, 542-575.

Diener, E., Emmons, R. A., Larsen, R. J., \& Griffin, S. (1985). The satisfaction with life scale. Journal of Personality Assessment, 49, 71-75.

Garcia, D. (2011) Adolescents' happiness: The role of the affective temperament model on 409 memory and apprehension of events, subjective well-being, and psychological wellbeing. Ph.D. Thesis, University of Gothenburg, Gothenburg. 
411 Garcia, D. (2012). The Affective Temperaments: Differences between Adolescents in the Big 412 Five Model and Cloninger's Psychobiological Model of Personality. Journal of 413 Happiness Studies, 13, 999- 1017. DOI: 10.1007/s10902-011-9303-5.

414 Garcia, D. (2013). La vie en Rose: High Levels of Well-Being and Events Inside and Outside 415 Autobiographical Memory. Journal of Happiness Studies. DOI: 10.1007/s10902-013416 9443-x.

417 Garcia, D., Anckarsä̈er, H., \& Lundstrom, S. (2013). Self-directedness and Cooperativeness, 418 psychosocial dysfunction and suffering in ESSENCE. The Scientific World Journal. DOI: $10.1155 / 2013 / 416981$.

420 Garcia, D., \& Archer, T. (2012). Adolescent Life Satisfaction and Well-Being. Journal of 421 Alternative Medicine Research, 4, 271-279.

422 Garcia, D., Ghiabi, B., Moradi, S., Siddiqui, A., \& Archer, T. (2013). The Happy Personality: A 423 Tale of Two Philosophies. In E. F. Morris \& M-A. Jackson (Eds.), Psychology of Personality (pp. 41-59). New York: Nova Science Publishers.

425 Garcia, D., Kerekes, N., Andersson-Arntén, A-C., \& Archer, T. (2012). Temperament, Character, 426 and Adolescents’ Depressive Symptoms: Focusing on Affect. Depression Research and

428 Garcia, D., Nima, A. A., \& Archer, T. (2013). International note: Temperament and Character's 429 430 Relationship to Subjective Well-Being in Salvadorian Adolescents and Young Adults. Journal of Adolescence, 36, 1115-1119. DOI: 10.1016/j.adolescence.2013.08.018.

431 Garcia, D., Lundström, S., Brändström, S., Råstam, M., Cloninger, C. R., Kerekes, N., Nilsson, 432 T., Anckarsäter, H. (2013). Temperament and Character in the Child and Adolescent 433 Twin Study in Sweden (CATSS): Comparison to the General Population, and Genetic 434 Structure Analysis. PLoS ONE 8(8): e70475. DOI: 10.1371/journal.pone.0070475. 
435 Garcia, D., \& Moradi, S. (2013). The Affective Temperaments and Well-Being: Swedish and 436 Iranian Adolescents' Life Satisfaction and Psychological Well-Being. Journal of 437 Happiness Studies, 14, 689-707. DOI: 10.1007/s10902-012-9349-z.

438 Garcia, D., \& Siddiqui, A. (2009a). Adolescents' Affective Temperaments: Life Satisfaction, 439 Interpretation and Memory of events. The Journal of Positive Psychology, 4, 155-167. DOI: $10.1080 / 17439760802399349$.

Garcia, D., \& Siddiqui, A. (2009b). Adolescents’ Psychological Well-Being and Memory for Life 442 Events: Influences on Life Satisfaction with Respect to Temperamental Dispositions. Journal of Happiness Studies, 10, 387-503. DOI: 10.1007/s10902-008-9096-3.

444 Garcia, D., \& Sikström, S. (2013). Quantifying the Semantic Representations in Adolescents' 445 Memories of Positive and Negative Life Events. Journal of Happiness Studies, 14, 1309-1323. DOI: 10.1007/s10902-012-9385-8.

447 Garcia, D., Rosenberg, P., Erlandsson, A., \& Siddiqui, A. (2010). On Lions and Adolescents: 448 Affective Temperaments and the Influence of Negative Stimuli on Memory. Journal of Happiness Studies, 11, 477-495. DOI: 10.1007/s10902-009-9153-6.

450 Higgins, E. T. (1997). Beyond pleasure and pain. American Psychologist, 52, 1280-1300.

451 Horton, J. J., Rand, D. G., \& Zeckhauser, R. J. (2011). The online laboratory: conducting 452 experiments in a real labor market. Experimental Economics, 14, 399-425.

453 Huppert, F. A., \& Whittington, J. E. (2008). Evidence for the independence of positive and 454 negative well- being: implications for quality of life assessment. British Journal of

456 Jimmefors, A., Garcia, D., \& Archer, T. (In press). Locomotion (Empowering) and Assessment 457 (Disempowering) Self-reglatory Dimensions as a Function of Affective profiles in High School Students. 
Johansson, R., Lyssarides, C., Andersson, G., \& Rousseau, A. (2013). Personality change after interner-delivered cognitive behavior therapy for depression.PeerJ 1:e39. DOI: 10.7717/peerj.39.

Kashdan, T. B., Biswas-Diener, R., \& King, L. A. (2008). Reconsidering happiness: The costs of distinguishing between hedonics and eudaimonia. The Journal of Positive Psychology, 3, 219-233.

Kjell ONE. 2011. Sustainable well-being: a potential synergy between sustainability and wellbeing research. Review of General Psychology 15:255-266 DOI 10.1037/a0024603.

Kjell, O. N. E., Hefferon, K., Garcia, D., \& Sikström, S. (2013). Enhancing Environmental and Social Sustainability: Attuned with Life Scale as a complement to Satisfaction with Life. Third World Congress on Positive Psychology. Los Angeles, California, USA.

Kjell, O. N. E., Nima, A. A., Sikström, S., Archer, T., \& Garcia, D. (2013). Iranian and Swedish Adolescents: Differences in Personality Traits and Well-Being. PeerJ 1:e197. DOI: 10.7717/peerj.197.

Karlsson, E., \& Archer, T. (2007). Relationship between personality characteristics and affect: Gender and affective personality. Individual Differences Research, 5, 44-58.

Kunst, M. J. J. (2011).Affective personality type, post-traumatic stress disorder symptom severity and post-traumatic growth in victims of violence. Stress and Health, 27, 42-51.

Lavrakas, P. J. (2008). Encyclopedia of Survey Research Methods. Sage: London.

Lindahl, M., \& Archer, T. (2013). Depressive expression and anti-depressive protection in adolescence: Stress, positive affect, motivation and self-efficacy. Psychology, 4, 495505.

MacDonald, S., \& Kormi-Nouri, R. (2013).The affective personality, sleep, and autobiographical memories. The Journal of Positive Psychology: Dedicated to furthering research and promoting good practice, $8,305-313$. 
484 Nima, A. A., Archer, T., \& Garcia, D. (2012). Adolescents' happiness-increasing Strategies, 485 Temperament, and Character: Mediation models on Subjective Well-Being. Health, 4, 486 802-810. DOI: 10.4236/health.2012.410124.

487 Nima, A. A., Archer, T., \& Garcia, D. (2013). The Happiness-Increasing Strategies Scales in a 488 Sample of Swedish Adolescents.International Journal of Happiness and Development, $489 \quad 1,196-211$.

490 Nima, A. A., Rosenberg, P., Archer, T., \& Garcia, D. (2013). Anxiety, Affect, Self-esteem, and 491 Stress: Mediation and Moderation Effects on Depression. PLOS ONE. DOI: 10.1371/journal.pone.0073265.

493 Norlander, T., Bood, S.-Å., \& Archer, T. (2002). Performance during stress: Affective personality 494 age, and regularity of physical exercise. Social Behavior and Personality, 30, 495-508.

495 Norlander, T., Johansson, Å., \&Bood, S.-Å. (2005). The affective personality: Its relation to 496 quality of sleep, well-being and stress. Social Behavior and Personality, 33, 709-722.

497 Palomo, T., Beninger, R. J., Kostrzewa, R. M., \& Archer, T. (2008). Focusing on symtoms rather 498 than diagnoses in brain dysfunction: Conscious and nonconscious expression in impulsiveness and decision making. Neurotoxicity Research, 14, 1-20.

500 Palomo, T., Kostrzewa, R. M., Beninger, R. J., \& Archer, T. (2007). Treatment consideration and 501 manifest complexity in comorbid neuropsychiatric disorders.Neurotoxicity Research, 12, 43-60.

503 Paolacci, G., Chandler, J., \& Ipeirotis, P. G. (2010). Running experiments on Amazon Mechanical 504 Turk. Judgment and Decision Making, 5, 411-419.

505 Russell, J. A., \& Feldman Barrett, L. (1999). Core affect, prototypical emotional episodes, and 506 other things called emotion: Dissecting the elephant. Journal of Personality and Social $507 \quad$ Psychology, 76, 805-819. 
508 Ryan, R. M., \& Huta, V. (2009). Wellness as healthy functioning or wellness as happiness: The importance of eudaimonic thinking. The Journal of Positive Psychology: Dedicated to $510 \quad$ furthering research and promoting good practice, 4, 202-204.

511 Ryff, C. D. (1989). Happiness is everything, or is it? Explorations on the meaning of 512 psychological well-being. Journal of Personality and Social Psychology, 57, 10691081. Science, 4, 99-104. Journal of Personality and Social Psychology, 69, 719-727.

Ryff, C. D., \& Singer, B. (1998). The contours of positive human health. Psychological Inquiry, 9, 2-28.

Schütz, E., Archer, T. \& Garcia, D. (2013). Character Profiles and Adolescents' Self-reported Affect. Personality and Individual Differences, 54, 841-844. DOI: 10.1016/j.paid.2012.12.020.

523 Schütz, E., Garcia, D., \& Archer, T. (2014). Affective State, Stress, and Type A-personality as a

$524 \quad$ Function of Gender and Affective Profiles. International Journal of Research Studies in Psychology, 3, 51-64. DOI: 10.5861/ijrsp.2013.450

526 Schütz, E., Sailer, U., Nima, A., Rosenberg, P., AnderssonArntén, A-C., Archer, T., \& Garcia, D. (2013). The affective profiles in the USA: happiness, depression, life satisfaction, and happiness- increasing strategies. PeerJ1:e156. DOI 10.7717/peerj.156.

529 Shapiro, D. N., Chandler, J., \& Mueller, P. A. (2013). Using Mechanical Turk to Study Clinical Populations. Clinical Psychological Science, 1, 213-220.

531 Straume, L. V., \& Vittersø, J. (2012). Happiness, inspiration and the fully functioning person: 532 Separating hedonic and eudaimonic well-being in the workplace. The Journal of 

$387-398$.

535 Waterman, A. S. (2008). Reconsidering happiness: A eudaimonist's perspective. The Journal of 536 Positive Psychology: Dedicated to furthering research and promoting good practice, 3, 537 234-252.

538 Watson, D., Clark, L. A., \& Tellegen, A. (1988). Development and validation of brief measures of 539 positive and negative affect: The PANAS scale. Journal of Personality and Social 540 Psychology, 54, 1063-1070.

541 Yik, M. S. M., Russell, J. A., \& Feldman Barrett, L. (1999). Structure of self reported current 542 affect: Integration and beyond. Journal of Personality and Social Psychology, 77, 600$543 \quad 619$. 


\section{LEGENDS}

545 Table 1. Definition of the six dimensions of psychological well-being.

546 Table 2. Mean scores and sd in all six psychological well-being dimensions, psychological well547 being total score, and harmony in life score for each affective profile.

548 Table 3. Structural coefficients for the structural equation model of multi-group moderation

549 between affective profiles as moderator and psychological well-being dimensions on harmony in 550 life.

551 Figure 1. Structural equation model of the six dimensions of psychological well-being and 552 harmony in life via the self-destructive group. All correlations (between different psychological 553 well-being dimensions) and all paths (from the six dimensions of psychological well-being to

554 harmony in life) and their standardized parameter estimates. Chi-square $=.00 ; D F=00$;

555 comparative fit index $=1.00$; incremental fit index $=1.00$ and normed fit index $=1.00$. e $=$ error.

556 Red standardized parameter estimates of regression weights are significant at the $p<.001$ level $(n$ $557=137)$.

558 Figure. 2. Structural equation model of the six dimensions of psychological well-being and 559 harmony in life via low affective group. All correlations (between different psychological well560 being dimensions) and all paths (from the six dimensions of psychological well-being to harmony 561 in life) and their standardized parameter estimates. Chi-square $=.00 ; D F=00$; comparative fit 562 index $=1.00$; incremental fit index $=1.00$ and normed fit index $=1.00$. $\mathrm{e}=$ error. Red 
563 standardized parameter estimates of regression weights are significant at the $p<.001$ level $(n=$

564 66).

565 Figure 3. Structural equation model of the six dimensions of psychological well-being and

566 harmony in life via high affective group. All correlations (between different psychological well-

567 being dimensions) and all paths (from the six dimensions of psychological well-being to harmony

568 in life) and their standardized parameter estimates. Chi-square $=.00 ; D F=00$; comparative fit

569 index $=1.00$; incremental fit index $=1.00$ and normed fit index $=1.00$. $\mathrm{e}=$ error. Red

570 standardized parameter estimates of regression weights are significant at the $p<.001$ level and

571 blue standardized parameter estimates of regression weights are significant at the $p<.05$ level $(n$ $572=137)$.

573 Figure 4. Structural equation model of the six dimensions of psychological well-being and 574 harmony in life via self-fulfilling group. All correlations (between different psychological well575 being dimensions) and all paths (from the six dimensions of psychological well-being to harmony 576 in life) and their standardized parameter estimates. Chi-square $=.00 ; D F=00$; comparative fit 577 index $=1.00$; incremental fit index $=1.00$ and normed fit index $=1.00$. e $=$ error. Red 578 standardized parameter estimates of regression weights are significant at the $p<.001$ level $(n=$ $579160)$.

580 Figure 5. Summary of the results showing the differences between affective profiles in the 6 581 dimensions of psychological well-being and harmony in life. 


\section{Table 1 (on next page)}

Table 1. Definition of the six dimensions of psychological well-being. 
Table 1. Definition of the six dimensions of psychological well-being.

Psychological Well-Being

Dimension

\section{Definition}

Self-acceptance

Positive relations with others

Autonomy

Environmental mastery

Purpose in life

Personal growth
Emphasis on acceptance of the self and of one's past

life.

Having strong feelings of empathy and affection for

all human beings and as being capable of greater love, deeper friendship, and more complete identification with others and warm relating to others.

Expressions of internal locus of evaluation, thus not

looking to others for approval but evaluating oneself

by personal standards.

The individual's ability to choose or create

environments suitable to his or her psychic conditions.

Having goals, intentions, and a sense of direction, all

of which contribute to the feeling that life is

meaningful.

Emphasis to continued growth and the confronting of new challenges or tasks at different periods of life. 


\section{Table 2 (on next page)}

Table 2. Mean scores and sd in all six psychological well-being dimensions, psychological well-being total score, and harmony in life score for each affective profile. 
Table 2. Mean scores and sd in all six psychological well-being dimensions, psychological well-being total score, and harmony in life score for each affective profile.

\begin{tabular}{|c|c|c|c|c|c|}
\hline & $\begin{array}{l}\frac{0}{\frac{2}{0}} \\
\frac{0}{2} \\
\frac{0}{2}\end{array}$ & $\begin{array}{l}\text { Self-destructive } \\
\quad n=137\end{array}$ & $\begin{array}{c}\text { Low affective } \\
n=66\end{array}$ & $\begin{array}{c}\text { High affective } \\
n=137\end{array}$ & $\begin{array}{l}\text { Self-fulfilling } \\
\quad n=160\end{array}$ \\
\hline Positive relations with oth & ers & $3.57 \pm .99$ & $4.06 \pm .90^{\mathrm{a}}$ & $4.25 \pm .96^{\mathrm{a}}$ & $4.97 \pm .91^{\mathrm{a}, \mathrm{b}, \mathrm{c}}$ \\
\hline Environmental mastery & $\geq$ & $3.11 \pm 1.02$ & $4.16 \pm 1.08^{a}$ & $4.10 \pm .88^{\mathrm{a}}$ & $4.92 \pm .72^{\mathrm{a}, \mathrm{b}, \mathrm{c}}$ \\
\hline Self-acceptance & 을 & $2.88 \pm 1.06$ & $3.88 \pm 1.08^{\mathrm{a}}$ & $4.00 \pm .98^{\mathrm{a}}$ & $4.80 \pm .85^{\mathrm{a}, \mathrm{b}, \mathrm{c}}$ \\
\hline Autonomy & ¿ & $4.22 \pm .92$ & $4.60 \pm .88^{\mathrm{a}}$ & $4.41 \pm .85$ & $4.81 \pm .80^{\mathrm{a}, \mathrm{c}}$ \\
\hline Personal growth & 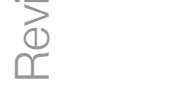 & $4.32 \pm .97$ & $4.44 \pm 1.03$ & $4.96 \pm .79^{\mathrm{a}, \mathrm{b}}$ & $5.31 \pm .64^{\mathrm{a}, \mathrm{b}, \mathrm{c}}$ \\
\hline Purpose in life & 3 & $4.06 \pm .93$ & $4.06 \pm .81$ & $4.45 \pm .84^{\mathrm{a}, \mathrm{b}}$ & $4.68 \pm .78^{\mathrm{a}, \mathrm{b}}$ \\
\hline Composite psychological & vell-being & $3.69 \pm .61$ & $4.20 \pm .66^{\mathrm{a}}$ & $4.37 \pm .54^{\mathrm{a}}$ & $4.91 \pm .48^{\mathrm{a}, \mathrm{b}, \mathrm{c}}$ \\
\hline Harmony in life & () & $3.25 \pm 1.28$ & $4.40 \pm 1.27^{\mathrm{a}}$ & $4.67 \pm 1.28^{\mathrm{a}}$ & $4.62 \pm .87^{\mathrm{a}, \mathrm{b}, \mathrm{c}}$ \\
\hline
\end{tabular}

Note: Values represent mean $\mathrm{s}$ ores \pm SD. $P<.01$.

a Bonferroni test: higher comparea to the self-destructive.

b Bonferroni test: higher compared to the low affective.

c Bonferroni test: higher compared to the high affective. 


\section{Table 3 (on next page)}

Table 3. Structural coefficients for the structural equation model of multi-group moderation between affective profiles as moderator and psychological well-being dimensions on harmony in life. 
Table 3. Standardized and unstandardized structural coefficients for the structural equation model of multi-group moderation between affective profiles as moderator and psychological well-being dimensions on harmony in life.

\begin{tabular}{|c|c|c|c|c|c|}
\hline \multicolumn{6}{|c|}{ Self-Destructive $n=137$} \\
\hline Predictor & Outcome & $\boldsymbol{\beta}$ & $\mathbf{S E}$ & $\boldsymbol{B}$ & $P$ \\
\hline $\begin{array}{l}\text { Positive } \\
\text { relations }\end{array}$ & & .12 & .08 & .10 & .12 \\
\hline $\begin{array}{l}\text { Environmenta } \\
\text { I mastery }\end{array}$ & & .46 & .10 & .37 & $<.001$ \\
\hline $\begin{array}{l}\text { Self- } \\
\text { acceptance }\end{array}$ & Harmony in life & .50 & .09 & .42 & $<.001$ \\
\hline Autonomy & & .00 & .08 & .00 & .95 \\
\hline $\begin{array}{l}\text { Personal } \\
\text { growth }\end{array}$ & & .09 & .09 & .07 & .30 \\
\hline Purpose in life & & -.06 & .09 & -.04 & .49 \\
\hline$R^{2}$ & .55 & & & & \\
\hline \multicolumn{6}{|c|}{ Low Affective $n=66$} \\
\hline Predictor & Outcome & $\beta$ & $\mathbf{S E}$ & $B$ & $P$ \\
\hline $\begin{array}{l}\text { Positive } \\
\text { relations }\end{array}$ & & -.17 & .12 & -.12 & .15 \\
\hline $\begin{array}{l}\text { Environmenta } \\
\text { I mastery }\end{array}$ & & .49 & .12 & .42 & $<.001$ \\
\hline $\begin{array}{l}\text { Self- } \\
\text { acceptance }\end{array}$ & Harmony in life & .67 & .12 & .57 & $<.001$ \\
\hline Autonomy & & .14 & .12 & .09 & .24 \\
\hline $\begin{array}{l}\text { Personal } \\
\text { growth }\end{array}$ & & .14 & .11 & .12 & .19 \\
\hline Purpose in life & & -.58 & .15 & -.37 & $<.001$ \\
\hline$R^{2}$ & .66 & & & & \\
\hline \multicolumn{6}{|c|}{ High Affective $n=137$} \\
\hline Predictor & Outcome & $\boldsymbol{\beta}$ & $\mathbf{S E}$ & $B$ & $P$ \\
\hline $\begin{array}{l}\text { Positive } \\
\text { relations }\end{array}$ & & .18 & .10 & .13 & .07 \\
\hline $\begin{array}{l}\text { Environmenta } \\
\text { I mastery }\end{array}$ & & .79 & .11 & .54 & $<.001$ \\
\hline $\begin{array}{l}\text { Self- } \\
\text { acceptance }\end{array}$ & Harmony in life & .23 & .11 & .17 & $<.05$ \\
\hline Autonomy & & -.13 & .10 & -.08 & .19 \\
\hline $\begin{array}{l}\text { Personal } \\
\text { growth }\end{array}$ & & .14 & .11 & .09 & .22 \\
\hline Purpose in life & & -.21 & .10 & -.14 & .05 \\
\hline$R^{2}$ & .47 & & & & \\
\hline \multicolumn{6}{|c|}{ Self-Fulfilling $n=160$} \\
\hline Predictor & Outcome & $\boldsymbol{\beta}$ & SE & $\boldsymbol{B}$ & $P$ \\
\hline $\begin{array}{l}\text { Positive } \\
\text { relations }\end{array}$ & Harmony in life & -.05 & .06 & -.06 & .39 \\
\hline $\begin{array}{l}\text { Environmenta } \\
\text { I mastery }\end{array}$ & & .48 & .10 & .40 & $<.001$ \\
\hline
\end{tabular}


Selfacceptance

Autonomy

Personal

growth

Purpose in life

.41

.08

.40

$<.001$

$R^{2}$

$-.07$

.07

$-.06$

.31

$.05 \quad .09$

$\begin{array}{ll}.03 & .59\end{array}$

$-.01$

.07

$-.01$

.93

Note: Significant regression weights are shown in bold type. 


\section{Figure 1}

Figure 1. Structural equation model of the six dimensions of psychological well-being and harmony in life via the self-destructive group.

All correlations (between different psychological well-being dimensions) and all paths (from the six dimensions of psychological well-being to harmony in life) and their standardized parameter estimates. Chi-square $=.00 ; D F=00$; comparative fit index $=1.00$; incremental fit index $=1.00$ and normed fit index $=1.00 . e=$ error. Red standardized parameter estimates of regression weights are significant at the $p<.001$ level $(n=137)$. 


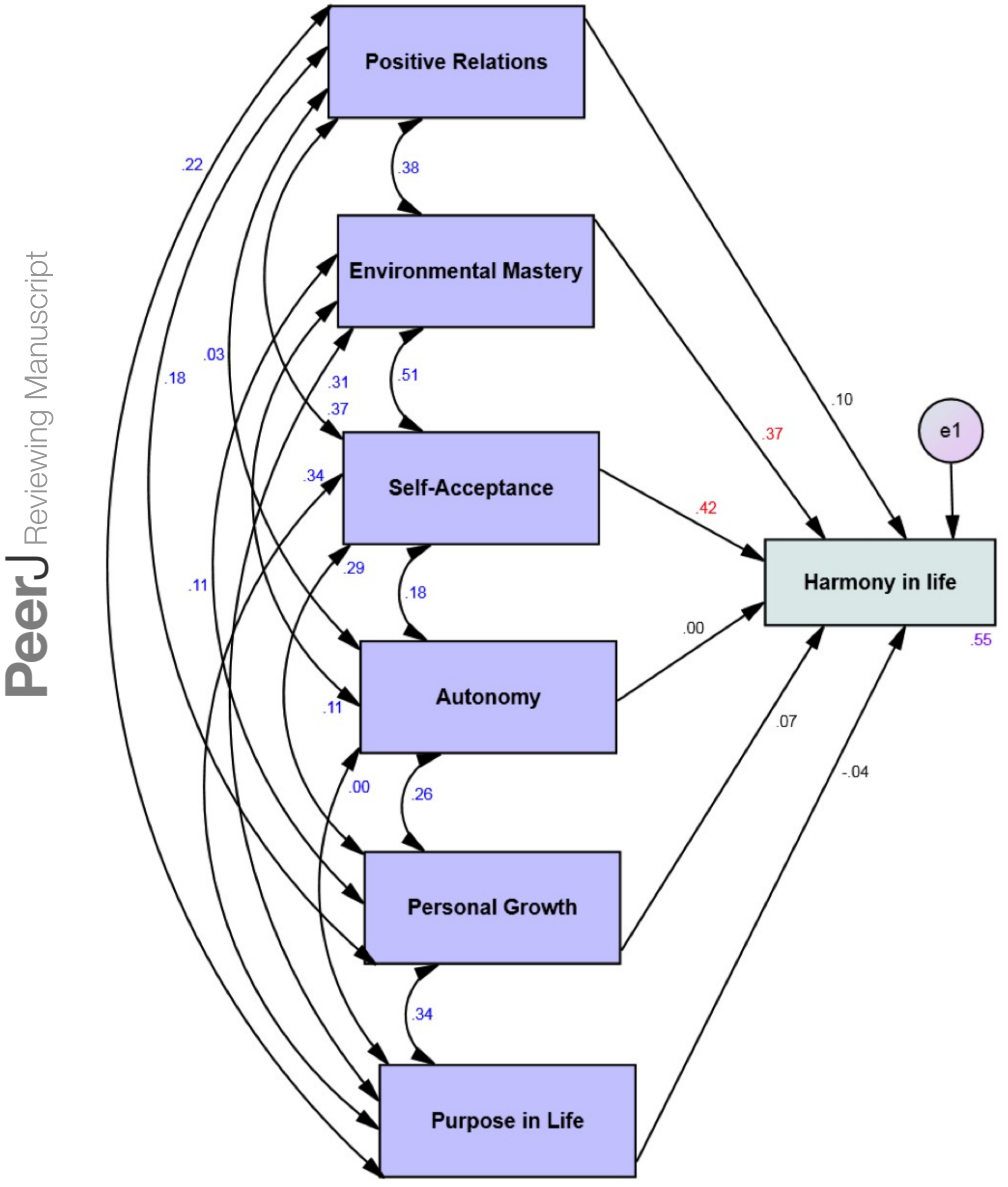




\section{Figure 2}

Figure. 2. Structural equation model of the six dimensions of psychological well-being and harmony in life via low affective group.

All correlations (between different psychological well-being dimensions) and all paths (from the six dimensions of psychological well-being to harmony in life) and their standardized parameter estimates. Chi-square $=.00 ; D F=00$; comparative fit index $=1.00$; incremental fit index $=1.00$ and normed fit index $=1.00 . e=$ error. Red standardized parameter estimates of regression weights are significant at the $p<.001$ level $(n=66)$. 


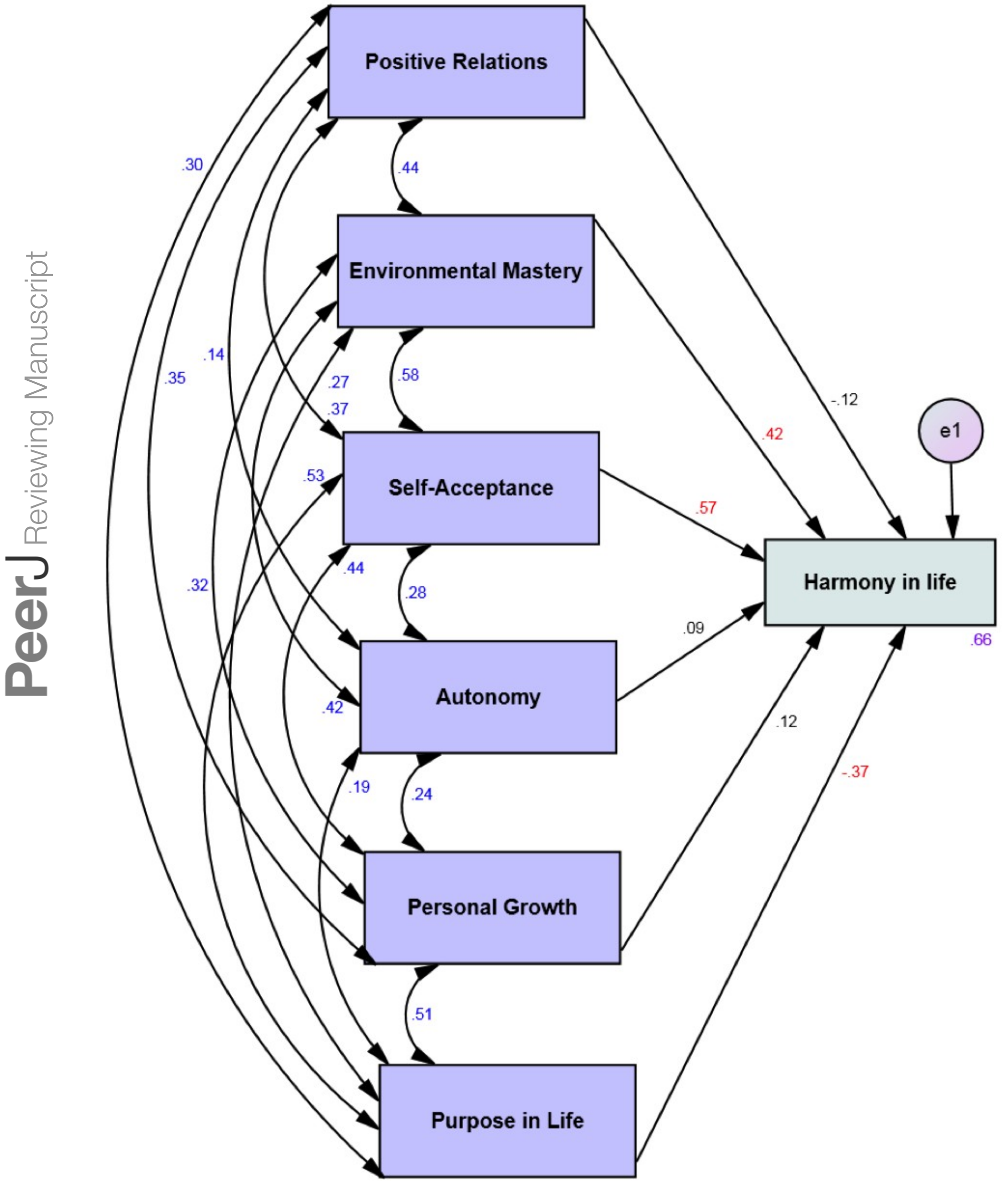




\section{Figure 3}

Figure 3. Structural equation model of the six dimensions of psychological well-being and harmony in life via high affective group.

All correlations (between different psychological well-being dimensions) and all paths (from the six dimensions of psychological well-being to harmony in life) and their standardized parameter estimates. Chi-square $=.00 ; D F=00$; comparative fit index $=1.00$; incremental fit index $=1.00$ and normed fit index $=1.00 . e=$ error. Red standardized parameter estimates of regression weights are significant at the $p<.001$ level and blue standardized parameter estimates of regression weights are significant at the $p<.05$ level $(n=137)$. 


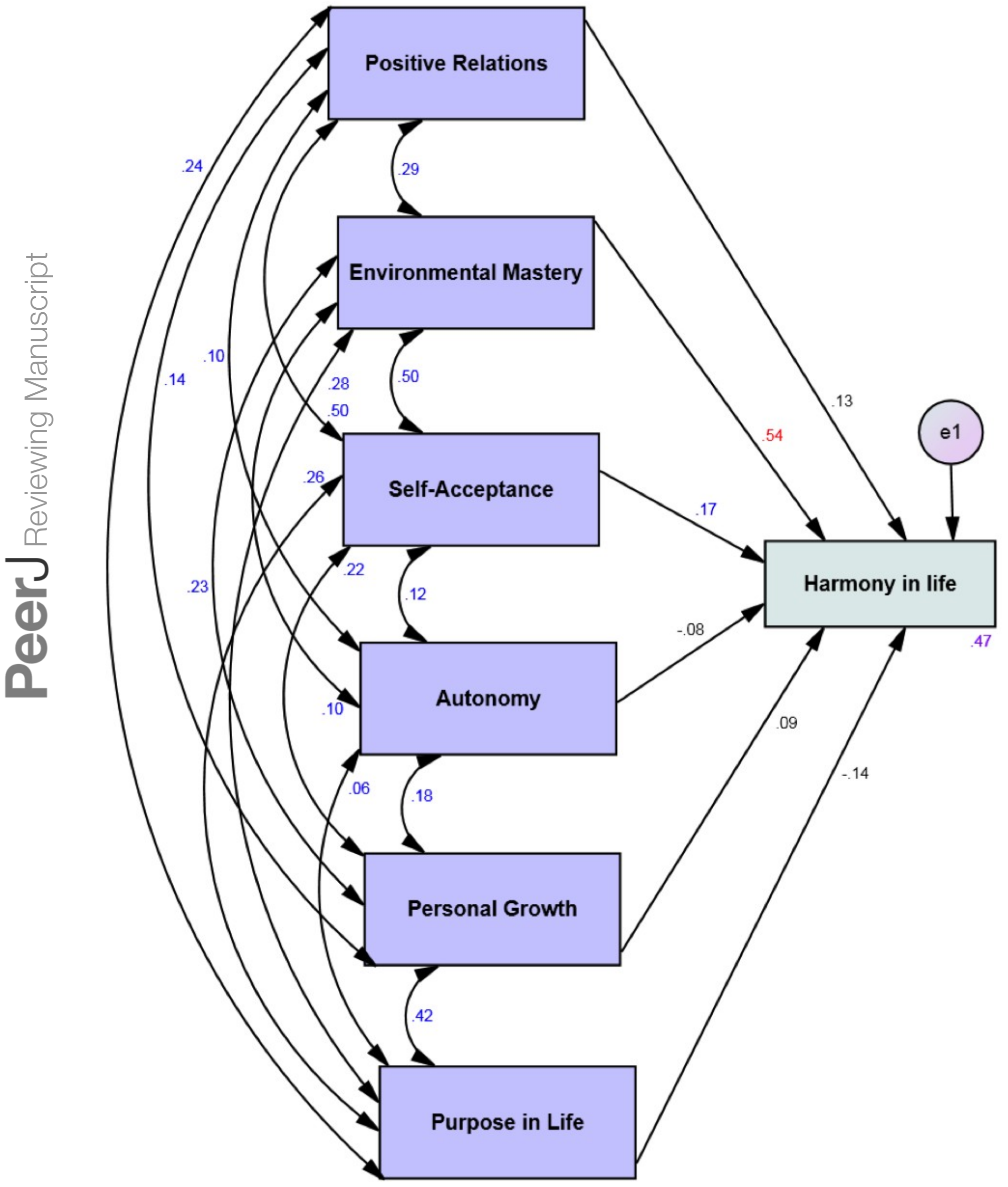




\section{Figure 4}

Figure 4. Structural equation model of the six dimensions of psychological well-being and harmony in life via self-fulfilling group.

All correlations (between different psychological well-being dimensions) and all paths (from the six dimensions of psychological well-being to harmony in life) and their standardized parameter estimates. Chi-square $=.00 ; D F=00$; comparative fit index $=1.00$; incremental fit index $=1.00$ and normed fit index $=1.00 . e=$ error. Red standardized parameter estimates of regression weights are significant at the $p<.001$ level $(n=160)$. 


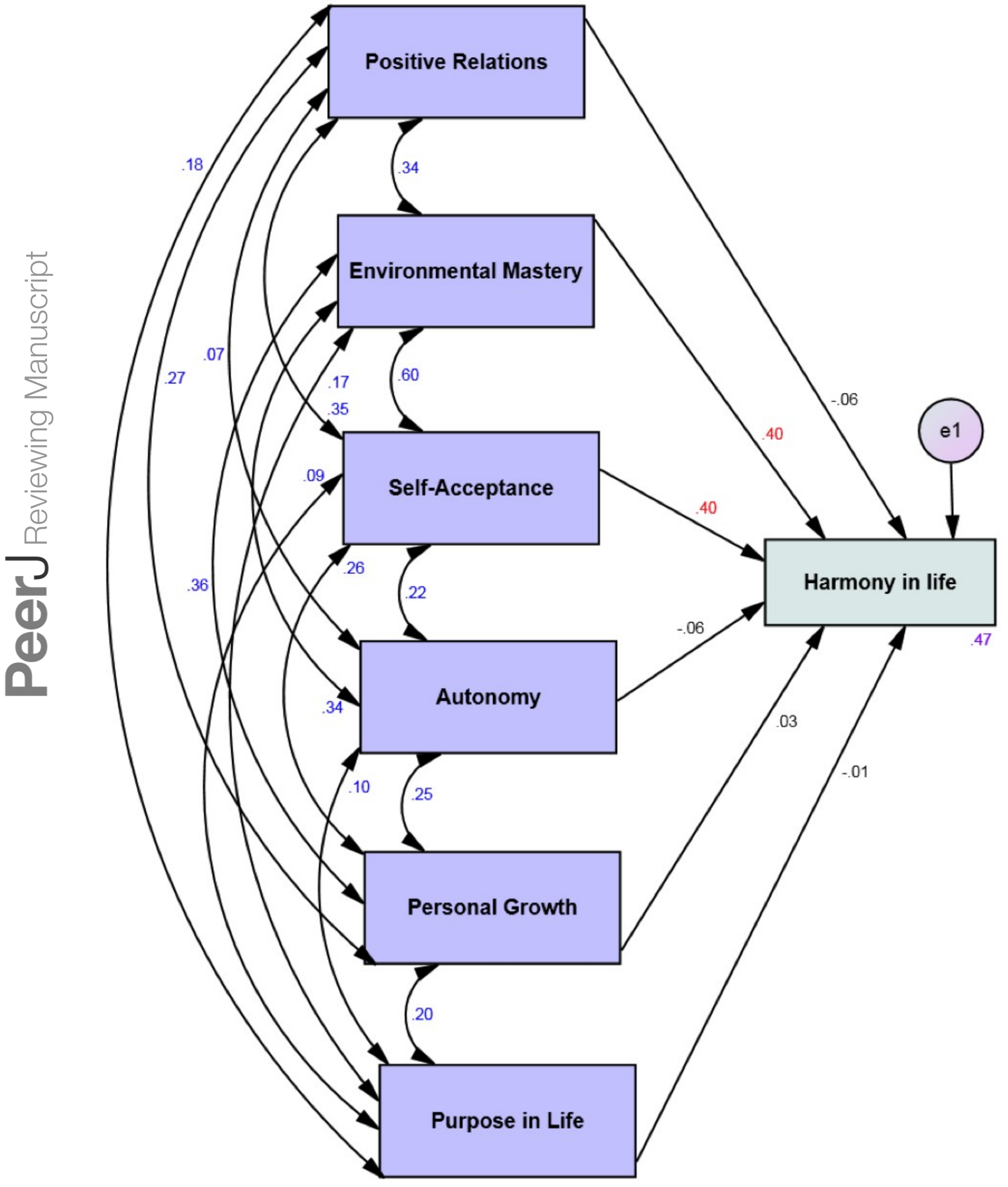




\section{Figure 5}

Figure 5. Summary of the results showing the differences between affective profiles in the 6 dimensions of psychological well-being and harmony in life. 


\section{High PA}

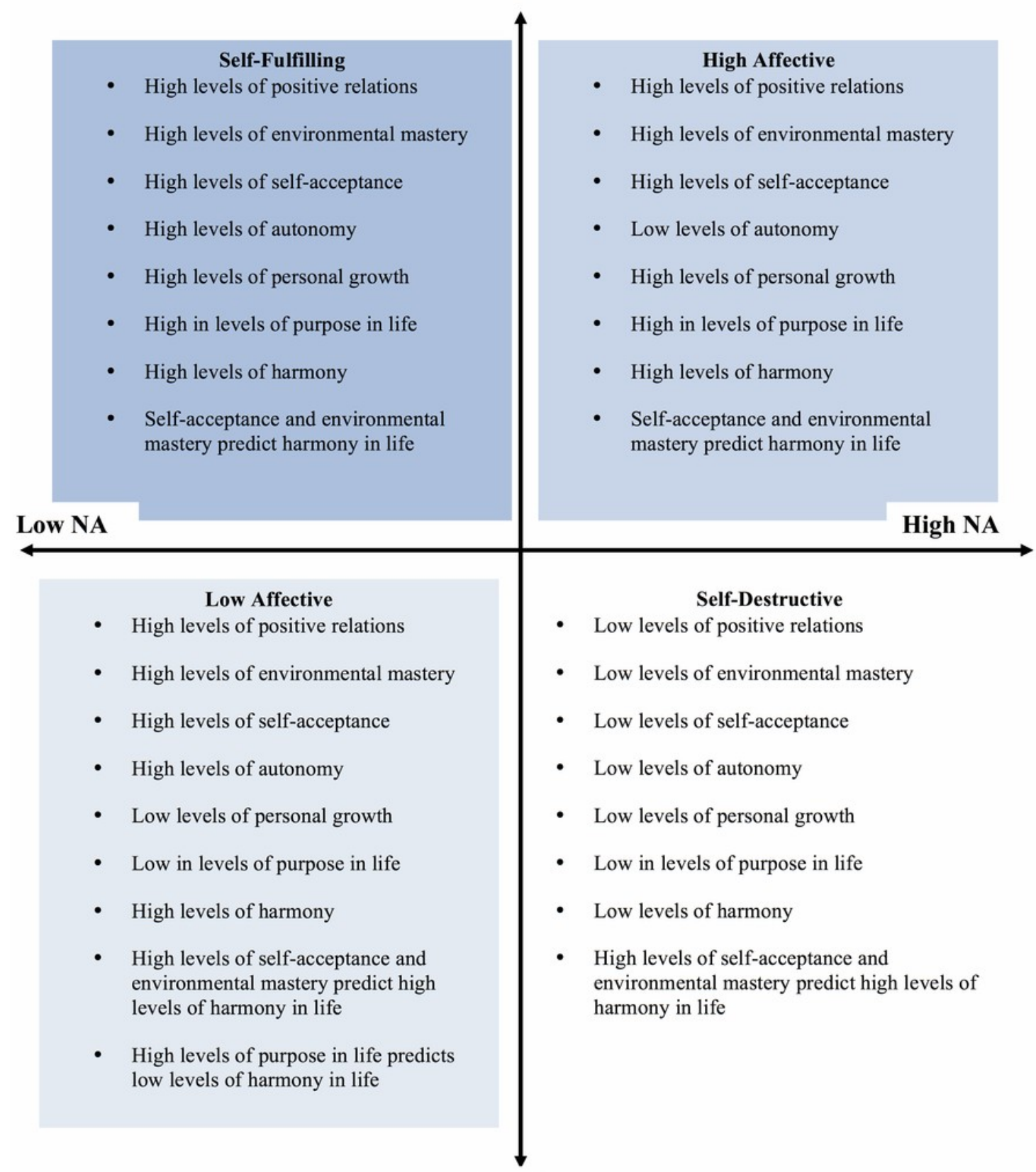

Low PA 